\title{
Interaction and main effects of physical and depressive symptoms on quality of life in Korean women seeking care for rectal prolapse: a cross-sectional observational study
}

\author{
Hee Moon ${ }^{1}$, Youngrye Park², Mili Kim³ ${ }^{3}$ Seonah Lee ${ }^{4}$ \\ 'Department of Nursing, Sunchon National University, Sunchon, Korea \\ ${ }^{2}$ Department of Nursing, Kunsan National University, Gunsan, Korea \\ ${ }^{3}$ Chonnam National University Hospital, Gwangju, Korea \\ ${ }^{4}$ College of Nursing, Chonnam National University, Gwangju, Korea
}

\begin{abstract}
Purpose: Rectal prolapse is still a relatively understudied medical condition, especially in women, whereas physical symptoms, depressive symptoms, and quality of life (QOL) in women with pelvic organ prolapse have been steadily studied. This study aimed to examine the interaction and main effects of physical and depressive symptoms on physical and mental QOL of women seeking care for rectal prolapse in Korea.

Methods: Ninety-two women with rectal prolapse were recruited from a colorectal surgery clinic of a tertiary teaching hospital in Gwangju, Korea. Physical symptoms related to rectal prolapse (pelvic organ prolapse distress, POPD; colorectal-anal distress, CRAD; and urinary distress, UD), depression, and QOL were measured. The data were analyzed using descriptive statistics, Pearson correlation coefficient, and two-way analysis of variance.

Results: The interaction between POPD symptoms and depressive symptoms ( $\mathrm{F}=4.51, p=.037)$ affected physical QOL. The interaction between POPD ( $\mathrm{F}=9.66, p=.003)$ and CRAD symptoms $(\mathrm{F}=7.48, p=.008)$, respectively, and depressive symptoms affected mental QOL. Depressive symptoms had a significant main effect on the physical QOL in the CRAD (F=6.22, $p=.014)$ and UD $(\mathrm{F}=6.01, p=.016)$ groups and on mental $\mathrm{QOL}$ in the UD group $(\mathrm{F}=24.54, p<.001)$.

Conclusion: Physical and depressive symptoms should be considered together to improve the QOL in women with rectal prolapse. Nursing interventions and medical treatments to decrease rectal prolapse-related physical and depressive symptoms are required to improve QOL in women with symptomatic rectal prolapse.
\end{abstract}

Keywords: Depressive symptoms; Physical symptoms; Quality of life; Rectal prolapse; Women
Received: November 3, 2021

Revised: December 8, 2021

Accepted: December 8, 2021

Corresponding author:

Seonah Lee

College of Nursing, Chonnam

National University, 160 Baekseo-

ro, Dong-gu, Gwangju 61469, Korea

Tel: +82-62-530-4945

E-mail: salee@jnu.ac.kr

\section{Introduction}

Rectal prolapse is a physically and emotionally distressing condition that can severely affect patients' daily lives although it is not life-threatening [1]. The prevalence of rectal prolapse increases with advancing age, with a higher prevalence in women
50 years of age or over [1]. In South Korea (hereafter Korea), the prevalence rate of patients diagnosed with pelvic organ prolapse including rectal prolapse increased by $3.76 \%$ from 2015 (2,362 patients) to 2019 (2,731 patients). Nearly $90 \%$ of the patients diagnosed with rectal prolapse were aged above 50 years, $34.7 \%$ were in their $70 \mathrm{~s}$, and $26.8 \%$ were in their $80 \mathrm{~s}$ [2]. The

This is an Open Access article distributed under the terms of the Creative Commons Attribution License (http://creativecommons.org/licenses/by/4.0) which permits unrestricted use, distribution, and reproduction in any medium, provided the original work is properly cited.

Copyright (c) 2021 Korean Society of Women Health Nursing 


\section{Summary statement}

\section{- What is already known about this topic?}

Previous studies reported relationships between prolapse-related physical symptoms, depressive symptoms, and the quality of life $(\mathrm{QOL})$ of women with pelvic organ prolapse. However, little is known about women with rectal prolapse.

\section{- What this paper adds}

There was an interaction effect of physical symptoms and depressive symptoms on QOL of women with rectal prolapse, and depression also had a significant main effect. Therefore, physical symptoms and depressive symptoms should be considered together to improve their QOL.

\section{- Implications for practice, education, and/or policy}

Proactive nursing interventions and medical treatments to simultaneously address prolapse-related physical symptoms and depressive symptoms are required to improve $\mathrm{QOL}$ in women seeking care for rectal prolapse.

relationship between pelvic floor disorders and age is thought to be due to aging changes in connective tissue integrity and neuromuscular degeneration $[1,3]$. Thus, age impacts the bothersome nature of rectal prolapse symptoms, especially as associated with functionality and quality of life (QOL) [1]. However, little is known about the prolapse-related physical and psychological problems and QOL in Korean women seeking care for rectal prolapse.

Rectal prolapse is a protrusion of part or all of the layers of the rectal wall toward or outside the anus [3]. It should not be confused with hemorrhoids, which are enlarged cushions of vascular tissue found within the anal canal in the submucosal space [4]. The underlying cause of rectal prolapse is unknown. However, known risk factors include lax muscles in the pelvic floor and anal canal, weak internal and external anal sphincters, diverse obstetric and gynecological surgeries, multiple vaginal deliveries, and straining $[3,4]$. Symptoms associated with rectal prolapse vary based on the anatomical defects or the degree of bowel dysfunction although some women have no symptoms despite the anatomical changes $[5,6]$. Defecatory symptoms are common [5], which include a protruding mass with bowel movements, mucous discharge, incomplete evacuation, constipation, fecal incontinence, and obstructed defecation $[5,7]$. These symptoms lead to pelvic floor dysfunction [3].

Prior studies have identified the myriad of negative effects stemming from pelvic organ prolapse, such as distress and embarrassment $[6,8]$ and how women often suffer in silence [9], despite experiencing depressive symptoms $[10]$ and low QOL $[11,12]$. Studies related to pelvic organ prolapse mainly reported relationships between prolapse-related physical symptoms and depressive symptoms and the main effects of these two groups of symptoms on the QOL of women with pelvic organ prolapse. However, limited studies provide an insight into the effects of physical and depressive symptoms on the QOL of women diagnosed with rectal prolapse. Specifically, there is insufficient evidence to suggest that the coexistence of physical symptoms and depressive symptoms worsens QOL in women with rectal prolapse. This increases the need to investigate the interaction effects of physical symptoms and depressive symptoms on the QOL of women with rectal prolapse. An interaction effect refers to the combined effect of two or more independent variables on at least one dependent variable. The combined interaction effect of two or more independent variables is not equal to the sum of their separate effects, which indicates being able to be greater or less than the sum of their separate effects [13]. On the other hand, a main effect is the effect of an independent variable on a dependent variable averaged, ignoring the effects of other independent variables [13]. The interpretation of a main effect is straightforward if the interaction effect is not significant [14].

The purpose of this study was to examine the interaction and main effects of physical symptoms and depressive symptoms on the physical and mental QOL of women seeking care for rectal prolapse.

\section{Methods}

Ethics statement: The study was approved by the Ethical Review Committee of Chonnam National University Hospital (CNUH-2016-308). Written informed consent was obtained from participants. 


\section{Study design}

This cross-sectional study used self-administered questionnaires via convenience sampling. This study was described in accordance with the STROBE (Strengthening the Reporting of Observational Studies in Epidemiology) guidelines (https:// www. strobe-statement.org).

\section{Participants}

Participants were recruited from the colorectal surgery clinic of a tertiary teaching hospital located in Gwangju, Korea. Eligibility criteria were women who were 50 years old or over, diagnosed with rectal prolapse, received nonsurgical treatment (e.g., monitoring disease status and pharmacotherapy), and understood the purpose of the study and the content of the questionnaire. Women who were scheduled for surgery due to severe symptoms of rectal prolapse were excluded, as surgical treatments would improve physical symptoms and QOL compared to women with nonsurgical treatments $[15,16]$. Women who had a history of any of the following were also excluded: colorectal or anal surgery with diagnoses other than rectal prolapse, radiotherapy for pelvic organs, neurologic disorders (e.g., spina bifida, multiple sclerosis, and stroke), and psychiatric disorders. Based on a significance level $(\alpha)$ of 0.05 , an effect size of 0.4 , and a statistical power of 0.95 using $\mathrm{G}^{*}$ Power 3.1 software, the sample size required was a minimum of 84 participants [17]. Considering dropouts, 102 women were recruited and after excluding ten cases due to incompleteness, a total of 92 women participated in the study.

\section{Measurement}

Physical symptoms

Physical symptoms related to rectal prolapse were measured using the three subscales of the Pelvic Floor Distress Inventory (PFDI)-20 developed by Barber et al. [18] and translated and modified by Yoo et al. [19] which measure symptoms experienced over the last 3 months: (1) the Pelvic Organ Prolapse Distress Inventory-6 (POPDI-6, six items) regarding bulging symptoms or heaviness in the pelvic area; (2) Colorectal-Anal Distress Inventory-8 (CRADI-8, eight items) regarding bowel problems; and (3) Urinary Distress Inventory-6 (UDI-6, six items) regarding urinary leakage or other lower urinary tract symptoms. The participant answers "yes" or "no" and then ranks the level of bother of each 'yes' item on a 4-point Likert scale (1, not at all to 4, quite a bit). Items answered with a "no" response receive a zero. The actual score is obtained by multiplying the mean of all of the responses with 25 . Thus, each subscale score of the PFDI-20 ranges from 0 to 100 . The higher the score, the greater the perceived level of distress. Cronbach's alpha coefficient was from 0.70 to 0.93 for all three subscales [19] and 0.79 in this study. Cronbach's alpha coefficients for pelvic organ prolapse distress (POPD), colorectal-anal distress (CRAD), and urinary distress (UD) were $0.60,0.69$, and 0.80 , respectively, in this study.

\section{Depression}

Depression was measured using the seven items from the Hospital Anxiety and Depression Scale (HADS) translated by Oh et al. [20]. The HADS was developed for use in hospital settings but was also valid when used in community settings [21]. Higher summed scores (range, 0-21) indicate greater perceived depression. A score of 0-7 is "normal," 8-10 is "mild," and 11-21 is "moderate to severe." Cronbach's alpha coefficient for depression items was 0.70 in community settings and 0.76 in clinical settings at development [22], 0.86 in a Korean sample [20], and 0.87 in this study.

\section{Quality of life}

QOL was measured using the Korean version [23] of the Short Form-12 Health Survey [24]. This 12-item instrument consists of two components: the physical component including physical functioning, role-physical (i.e., role limitations due to physical problems), bodily pain, and general health; and the mental component including vitality, social functioning, role-emotional (i.e., role limitations due to emotional problems), and mental health. Items are scored on a 2-point (1, yes and 2, no) or 6-point (1, all of the time to 6 , none of the time) Likert, with the scores of physical and mental component summary transformed into a 0 to 100 range, respectively, according to the scoring manual using Quality Metric Health Outcomes scoring software 5.0 [23,25]. Higher scores indicate higher QOL. Cronbach's alpha coefficients for the physical component summary and the mental component summary were 0.70 and 0.69 , respectively, in this study.

\section{Participants' characteristics}

With reference to previous studies $[15,26,27]$, the characteristics of the participants included age, body mass index (BMI), parity, birth delivery methods, a history of hysterectomy, ever having used midlife hormone therapy, and medical conditions including allergic rhinitis and chronic obstructive pulmonary disease. 


\section{Data collection}

The data were collected at a colorectal surgery clinic between January 9 and August 25, 2017. When patients arrived at the waiting room and waited for their appointment, a research associate $(\mathrm{MK})$ approached them and courteously asked them about participating in the study. For women who expressed interest, the researcher led them to the separate room and explained the study purpose, anonymity, and voluntary participation. After informed consent, participants filled out the questionnaires assisted by the researcher, when needed.

\section{Statistical methods}

The IBM SPSS ver. 23.0 (IBM Corp., Armonk, NY, USA) was used for the data analyses. Descriptive statistics were done for demographic data and the main variables. Correlations between physical symptoms, depressive symptoms, and physical and mental QOL were analyzed using Pearson's correlation coefficients. Participants were dichotomized into two groups depending upon the presence or absence of symptoms. The participants responding "somewhat,", "moderately,", or "quite a bit" to the POPDI and UDI were grouped as the POPD and the UD groups. Those who had no symptoms were considered the nonPOPD and non-UD groups. As all participants experienced colorectal-anal symptoms, the participants scoring less than the median value of 37.50 were grouped as the low CRAD group and the remaining participants were considered the high CRAD group. The responses to depressive symptoms were also dichotomized as non-depressed ( 0 to 7 points) or depressed ( $\geq 8$ points). The Kolmogorov-Smirnov test was used to test the normal distribution of the QOL data that was the dependent variable. The physical and mental QOL data were normally distributed as the $p$-values of the Kolmogorov-Smirnov test were .20 and .64, respectively, greater than .05. The total QOL data were also normally distributed with the $p$-value of .40 in the Kolmogorov-Smirnov test. Differences in QOL according to the characteristics of the participants were analyzed using the chi-squared test. The main effects and interaction effects of physical symptoms and depressive symptoms on the QOL were analyzed using two-way analysis of variance. Statistical significance was set at the level of the $p$-value less than .05 for all tests.

\section{Results}

\section{Characteristics of the participants}

The mean age of the 92 participants was $70.0 \pm 10.0$ years old and $51.1 \%$ were overweight or obese (Table 1 ). The median
Table 1. Characteristics of the participants ( $\mathrm{N}=92)$

\begin{tabular}{|c|c|c|}
\hline Variable & Categories & n $(\%)$ \\
\hline \multirow[t]{5}{*}{ Age (year) } & & Mean $\pm S D, 70 \pm 10.0$ \\
\hline & $50-59$ & $17(18.5)$ \\
\hline & $60-69$ & $26(28.3)$ \\
\hline & $70-79$ & $34(37.0)$ \\
\hline & $\leq 80$ & $15(16.3)$ \\
\hline \multirow{4}{*}{$\begin{array}{l}\text { Body mass index } \\
\left(\mathrm{kg} / \mathrm{m}^{2}\right)\end{array}$} & Underweight ( $\leq 18.5$ ) & $7(7.6)$ \\
\hline & $\begin{array}{l}\text { Normal weight } \\
(18.6-22.9)\end{array}$ & $38(41.3)$ \\
\hline & Overweight (23.0-24.9) & $21(22.8)$ \\
\hline & Obesity ( $\geq 25.0$ ) & $26(28.3)$ \\
\hline \multirow[t]{4}{*}{ Parity } & & Median (range), 3 (0-8) \\
\hline & 0 & $10(10.9)$ \\
\hline & $1-2$ & $17(18.5)$ \\
\hline & $\geq 3$ & 65 (70.7) \\
\hline \multirow[t]{2}{*}{ Delivery methods } & Vaginal delivery & $82(89.1)$ \\
\hline & Cesarean section & $10(10.9)$ \\
\hline \multirow[t]{2}{*}{ Hysterectomy } & Yes & $14(15.2)$ \\
\hline & No & $78(84.8)$ \\
\hline \multirow{2}{*}{$\begin{array}{l}\text { Midlife hormone } \\
\text { therapy ever taken }\end{array}$} & Yes & $14(15.2)$ \\
\hline & No & 78 (84.8) \\
\hline \multirow[t]{2}{*}{ Allergic rhinitis } & Yes & $17(18.5)$ \\
\hline & No & 75 (81.5) \\
\hline \multirow{2}{*}{$\begin{array}{l}\text { Chronic obstructive } \\
\text { pulmonary disease }\end{array}$} & Yes & $5(5.4)$ \\
\hline & No & $87(94.6)$ \\
\hline
\end{tabular}

parity value was 3 (range, $0-8$ ), $70.7 \%$ of the participants $(\mathrm{n}=65)$ had more than three children, and $89.1 \%(\mathrm{n}=82)$ experienced vaginal deliveries. Nearly $15 \%$ of the participants $(\mathrm{n}=14)$ answered "yes" to hysterectomy, 15.2\% ( $\mathrm{n}=14)$ midlife to hormone therapy, $18.5 \%(n=17)$ to allergic rhinitis, and 5.4\% $(\mathrm{n}=5)$ to chronic obstructive pulmonary disease. There were no differences in QOL according to the characteristics of the participants.

\section{Physical symptoms, depressive symptoms, and quality of life perceived by the participants}

The mean value for physical symptoms was 83.20 out of a total of 300 points (Table 2). In the subscales of the PFDI-20, the mean values in the POPD, CARD, and UD were 22.28, 38.27, and 22.19, respectively, out of a total of 100 points. The mean value for depressive symptoms was 7.83 out of a maximum of 21 points. Of 92 participants, $54.3 \%(n=50)$ reported the absence of depressive symptoms, $21.7 \%(\mathrm{n}=20)$ had mild, and 23.9\% ( $n=22)$ experienced moderate-to-severe depressive symptoms. The mean values of physical QOL and mental QOL 
Table 2. Perceptions of physical symptoms, depressive symptoms, and quality of life $(\mathrm{N}=92)$

\begin{tabular}{|c|c|c|c|c|c|}
\hline Variable & Categories & Mean (SD) & Range & Possible range & Frequency (\%) \\
\hline Pelvic floor distress symptoms & & $83.20(49.09)$ & $6.25-233.33$ & $0-300$ & \\
\hline Pelvic organ prolapse distress & & $22.28(19.81)$ & $0-83.33$ & $0-100$ & \\
\hline Colorectal-anal distress & & $38.72(18.88)$ & $0-81.25$ & $0-100$ & \\
\hline Urinary distress & & $22.19(23.16)$ & $0-100$ & $0-100$ & \\
\hline Depressive symptoms & & $7.83(4.67)$ & $0-21$ & $0-21$ & \\
\hline & Normal & $4.2(2.10)$ & $0-7$ & $0-7$ & $50(54.3)$ \\
\hline & Mild & $8.95(0.74)$ & $8-10$ & $8-10$ & $20(21.7)$ \\
\hline & Moderate to Severe & $14.36(3.28)$ & $11-21$ & $11-21$ & $22(23.9)$ \\
\hline Physical quality of life & & $38.06(9.78)$ & $20.11-57.29$ & $0-100$ & \\
\hline Mental quality of life & & $42.50(9.54)$ & $24.01-59.64$ & $0-100$ & \\
\hline
\end{tabular}

Table 3. Correlations between physical symptoms, depressive symptoms, and quality of life $(\mathrm{N}=92)$

\begin{tabular}{|c|c|c|c|c|c|}
\hline Variable & $\begin{array}{l}\text { Pelvic organ prolapse } \\
\text { distress }\end{array}$ & $\begin{array}{l}\text { Colorectal-anal } \\
\text { distress }\end{array}$ & $\begin{array}{l}\text { Urinary } \\
\text { distress }\end{array}$ & $\begin{array}{l}\text { Depressive } \\
\text { symptoms }\end{array}$ & $\begin{array}{c}\text { Physical } \\
\text { quality of life }\end{array}$ \\
\hline Pelvic organ prolapse distress & 1 & & & & \\
\hline Colorectal-anal distress & $0.33^{* *}$ & 1 & & & \\
\hline Urinary distress & $0.54^{* * *}$ & $0.44^{* *}$ & 1 & & \\
\hline Depressive symptoms & $0.48^{* * *}$ & $0.38^{* * *}$ & $0.37^{* * *}$ & 1 & \\
\hline Physical quality of life & $-0.38^{* * *}$ & $-0.33^{* *}$ & $-0.35^{* *}$ & $-0.49^{* * *}$ & 1 \\
\hline Mental quality of life & $-0.41^{* * *}$ & $-0.38^{* * *}$ & $-0.31^{* *}$ & $-0.73^{* * *}$ & $0.48^{* * *}$ \\
\hline
\end{tabular}

${ }^{* *} p<.01,{ }^{* * *} p<.001$.

Table 4. Differences in physical and mental quality of life according to the presence and absence of physical and depressive symptoms ( $\mathrm{N}=92$ )

\begin{tabular}{lcccccccc}
\hline \multirow{2}{*}{ Group } & \multicolumn{9}{c}{ Mean (SD) } \\
\cline { 2 - 9 } & Non-POPD & POPD & Low CRAD & High CRAD & Non-UD & UD & Non-depression & Depression \\
\hline Physical quality of life & $40.56(7.95)$ & $37.54(0.09)$ & $39.34(9.91)$ & $33.73(8.14)$ & $41.15(9.53)$ & $37.46(9.78)$ & $41.33(8.99)$ & $34.17(9.34)$ \\
Mental quality of life & $46.36(6.18)$ & $41.69(9.95)$ & $44.13(9.36)$ & $37.01(8.14)$ & $46.84(8.37)$ & $41.66(9.57)$ & $48.03(7.59)$ & $35.94(7.19)$
\end{tabular}

CRAD: Colorectal-anal distress; POPD: pelvic organ prolapse distress; UD: urinary distress.

were 38.06 and 42.50, respectively, out of a total of 100 points. The POPD, CRAD, UD, and depressive symptoms were positively correlated with each other, but negatively correlated with the physical and mental QOL. Physical QOL was positively correlated with mental QOL (Table 3).

\section{Differences in quality of life according to physical symptoms and depressive symptoms}

QOL was examined according to the presence and absence of POPD symptoms and depressive symptoms (Table 4). The total mean values of the physical QOL were higher in the non-depression group (41.33 points) and the non-POPD group (40.56 points) than in the depression group ( 34.17 points) and the POPD group (37.54 points), respectively. The total mean values of the mental QOL were higher in the non-depression group
(48.03 points) and the non-POPD group (46.36 points) than in the depression group ( 35.94 points) and the POPD group (41.69 points), respectively. The total mean values of both physical and mental QOL were higher in the low CRAD group and the non-UD group than in the high CRAD group and the UD group.

\section{Main effects of physical symptoms and depressive symptoms on quality of life}

Depressive symptoms had a significant main effect on physical QOL in the CRAD group $(\mathrm{F}=6.22, p=.014)$ and the UD group $(\mathrm{F}=6.01, p=.016)$. Depressive symptoms also had a main effect on mental QOL in all three groups: the POPD group $(\mathrm{F}=12.71$, $p=.001)$, the CRAD group $(\mathrm{F}=18.30, p<.001)$, and the UD group $(\mathrm{F}=24.54, p<.001)$. The POPD symptoms and CRAD 
Table 5. Main and interaction effects of physical symptoms and depressive symptoms on physical and mental quality of life ( $\mathrm{N}=92$ )

\begin{tabular}{|c|c|c|c|c|c|c|c|c|c|c|}
\hline \multirow{2}{*}{ Source } & \multicolumn{5}{|c|}{ Physical QOL } & \multicolumn{5}{|c|}{ Mental QOL } \\
\hline & SS & $d f$ & MS & $\mathrm{F}$ & $p$ & SS & $d f$ & MS & $\mathrm{F}$ & $p$ \\
\hline Model 1 & $1,579.43$ & 3 & 526.48 & 6.50 & .001 & $3,902.61$ & 3 & $1,300.87$ & 26.15 & $<.001$ \\
\hline POPD symptoms & 151.29 & 1 & 151.29 & 1.87 & .175 & 254.45 & 1 & 254.45 & 5.12 & .026 \\
\hline Depressive symptoms & 111.81 & 1 & 111.81 & 1.38 & .243 & 632.06 & 1 & 632.06 & 12.71 & .001 \\
\hline POPD $\times$ depressive symptoms & 365.29 & 1 & 365.29 & 4.51 & .037 & 480.28 & 1 & 480.28 & 9.66 & .003 \\
\hline Error & $7,130.92$ & 88 & 81.03 & & & $4,404.89$ & 88 & 50.05 & & \\
\hline Total & $8,710.34$ & 91 & & & & $8,279.78$ & 91 & & & \\
\hline Model 2 & $1,355.38$ & 3 & 451.79 & 5.41 & .002 & $3,874.89$ & 3 & $1,291.63$ & 25.80 & $<.001$ \\
\hline CRAD symptoms & 174.62 & 1 & 174.62 & 2.09 & .152 & 324.27 & 1 & 324.27 & 6.48 & .013 \\
\hline Depressive symptoms & 520.10 & 1 & 520.10 & 6.22 & .014 & 915.74 & 1 & 915.74 & 18.30 & $<.001$ \\
\hline CRAD $\times$ depressive symptoms & 1.03 & 1 & 1.03 & .01 & .912 & 374.27 & 1 & 374.27 & 7.48 & .008 \\
\hline Error & $7,354.96$ & 88 & 83.58 & & & $4,825.07$ & 88 & 54.83 & & \\
\hline Total & $8,710.34$ & 91 & & & & $8,279.78$ & 91 & & & \\
\hline Model 3 & $1,261.78$ & 3 & 420.59 & 4.97 & .003 & $3,503.4$ & 3 & $1,167.80$ & 21.52 & $<.001$ \\
\hline UD symptoms & 87.48 & 1 & 87.48 & 1.03 & .312 & 168.57 & 1 & 168.57 & 3.11 & .081 \\
\hline Depressive symptoms & 509.04 & 1 & 509.04 & 6.01 & .016 & $1,331.79$ & 1 & $1,331.79$ & 24.54 & $<.001$ \\
\hline UD $\times$ depressive symptoms & 1.50 & 1 & 1.50 & .02 & .894 & 21.99 & 1 & 21.99 & .41 & .526 \\
\hline Error & $7,448.56$ & 88 & 84.64 & & & $4,776.38$ & 88 & 54.28 & & \\
\hline Total & $8,710.34$ & 91 & & & & $8,279.78$ & 91 & & & \\
\hline
\end{tabular}

CRAD: Colorectal-anal distress; MS, mean square; POPD: pelvic organ prolapse distress; QOL: quality of life; SS, sum of squares; UD: urinary distress.

symptoms had significant main effects on mental QOL $(\mathrm{F}=5.12$, $p=.026$ and $\mathrm{F}=6.48, p=.013$, respectively) (Table 5).

\section{Interaction effects of physical symptoms and depressive symptoms on quality of life}

Presented as graphs to ease detection of interaction effects (lines not parallel or either intersecting, converging, or diverging) [28], the interaction between the POPD symptoms and depressive symptoms significantly affected both physical $(\mathrm{F}=4.51$, $p=.037)$ and mental QOL $(\mathrm{F}=9.66, p=.003)$ (Table 5; Figures $1 \mathrm{~A}, 1 \mathrm{D})$. The interaction between the CRAD symptoms and depressive symptoms significantly affected mental QOL $(\mathrm{F}=7.48, p=.008)$ (Table 5, Figure 1E). Thus, the non-parallel lines in Figures $1 \mathrm{~A}, 1 \mathrm{D}$, and $1 \mathrm{E}$ showed that there were interactive effects.

However, the interaction between the CRAD symptoms and depressive symptoms did not significantly affect physical QOL $(\mathrm{F}=0.01, p=.912)$ (Table 5, Figure 1B). The interaction between UD symptoms and depressive symptoms did not significantly affect physical QOL $(\mathrm{F}=0.02, p=.894)$ nor mental QOL $(\mathrm{F}=0.41, p=.526)$ (Table 5; Figures $1 \mathrm{C}, 1 \mathrm{~F})$. The parallel lines or non-crossing line in Figures $1 \mathrm{~B}, 1 \mathrm{C}$, and $1 \mathrm{~F}$ show that there were no interaction effects.

\section{Discussion}

This study analyzed the interaction and main effects of physical symptoms and depressive symptoms on the physical and mental QOL of women seeking care for rectal prolapse. There was an interaction effect between POPD symptoms and depressive symptoms on the physical QOL of women with rectal prolapse. There was also an interaction effect between POPD symptoms and CRAD symptoms, respectively, and depressive symptoms on the mental QOL. Therefore, POPD and CRAD symptoms and depressive symptoms should be simultaneously considered as factors affecting the physical or mental QOL of women seeking care for rectal prolapse. The results also showed that depressive symptoms had a significant main effect on the physical QOL of women in the CRAD and UD groups, and on the mental QOL of women in the UD group. In Figures $1 \mathrm{~B}, 1 \mathrm{C}$, and $1 \mathrm{~F}$ there were no interaction, and depressive symptoms had a true (statistically significant) main effect on the physical or mental QOL of women with rectal prolapse. This means that physical and mental QOL were higher in women without depressive symptoms than those their depressed counterparts.

On the other hand, when the interaction is significant and crosses, it is not appropriate to try to interpret main effects because the main effects are not constant but vary according to the 
A Interaction of POPD and depression

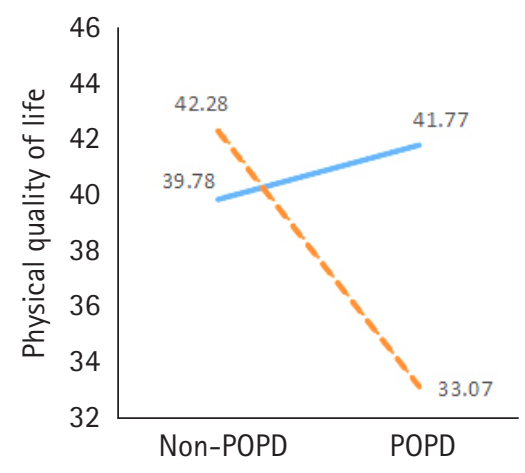

D Interaction of POPD and depression

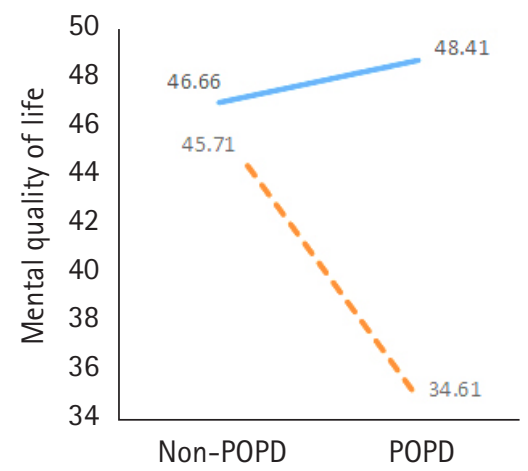

B

Interaction of CRAD and depression

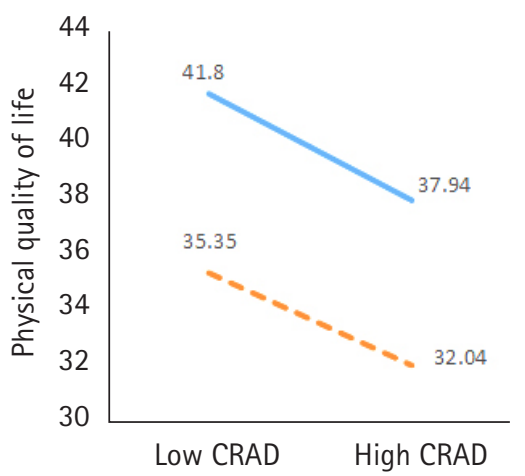

E Interaction of CRAD and depression

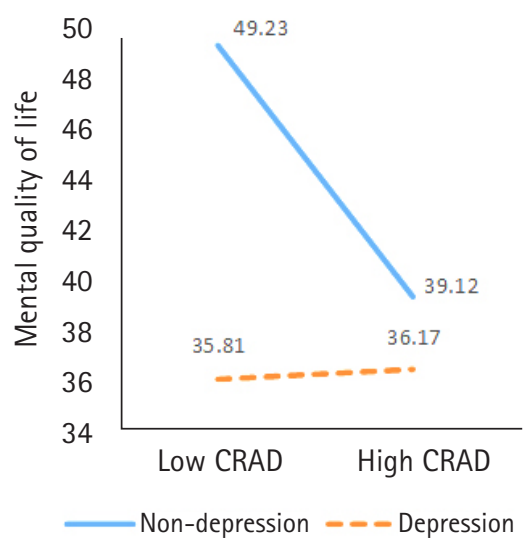

(C)

Interaction of UD and depression

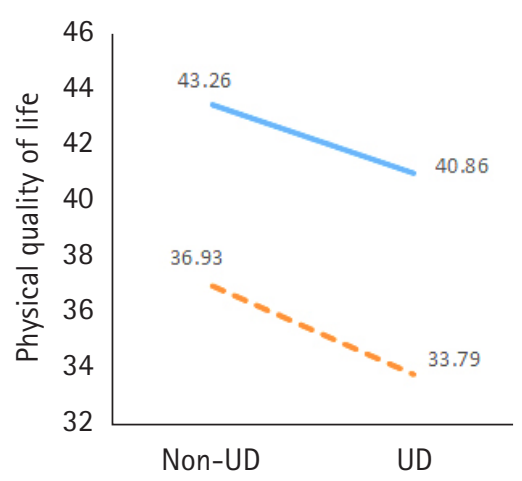

F Interaction of UD and depression

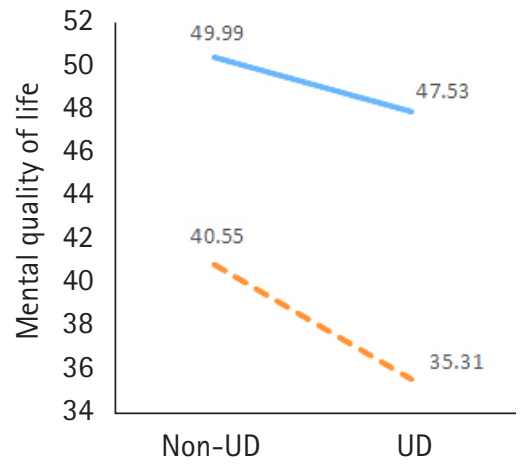

Figure 1. Main and interaction effects of physical symptoms and depressive symptoms on quality of life. $(A, B, C)$ Interaction effects on physical quality of life. (D, E, F) Interaction effects on mental quality of life.

CRAD: Colorectal-anal distress; POPD: pelvic organ prolapse distress; UD: urinary distress.

independent variables that interact with each other [14]. Usually, crossing lines mean no main effect [14]. In Figure 1A, the lines crossed each other, indicating the interaction between the POPD symptoms and depressive symptoms. Therefore, it would be misleading to say that the POPD symptoms and depressive symptoms each had the independent main effect on physical QOL. In Figures 1D and 1E, although the lines did not intersect, there was the interaction effect between depressive symptoms and POPD symptoms with CRAD symptoms, respectively, as well as with mental QOL. These interaction effects should be considered primary over the main effects of the POPD and CRAD symptoms on mental QOL.

To our knowledge, there has been no study that investigated the interaction and main effects related to physical symptoms, depressive symptoms, and QOL in women with rectal prolapse. However, as previous studies reported the relationships of de- pressive symptoms and physical symptoms on the QOL of women seeking care for diseases related to pelvic organ prolapse, the results of those studies were consistent with this study. In previous studies, pelvic organ prolapse symptoms were closely correlated with depressive symptoms [8,11,29]. Especially, depressive symptoms were highly prevalent among women with fecal and urinary incontinence and obstetric fistula attributable to pelvic organ prolapse [10]. Further, the physical symptoms attributable to prolapse were risk factors independently associated with the development of depressive symptoms in women with pelvic organ prolapse $[8,29]$. Women's subjective feeling regarding not only the influence of prolapse itself on their QOL but also the impact of lower urinary tract symptoms and bowel dysfunction on their QOL were highly associated with depressive symptoms [8]. In the same vein, physical symptoms and depressive symptoms were independent risk factors contribut- 
ing to the low QOL $[11,12]$. Pizarro-Berdichevsky et al. [11] reported that depressive symptoms, rather than anatomical abnormalities or objective clinical findings, determined how patients experience pelvic organ prolapse symptoms. Mazi et al. [29] suggested a bidirectional correlation between prolapse-related physical symptoms and depressive symptoms in women with pelvic organ prolapse as one of the two might represent the cause or effect on the other.

Based on the interaction of prolapse-related physical symptoms and depressive symptoms, it can be said that physical symptoms caused by rectal prolapse are more likely to induce depressive symptoms, and depressive symptoms also tend to exacerbate the physical symptoms due to rectal prolapse. Therefore, nursing interventions and medical treatments to decrease rectal prolapse-related physical symptoms and depressive symptoms at the same time are required to improve the $\mathrm{QOL}$ in women seeking care for symptomatic rectal prolapse. Further, screening for depressive symptoms should be implemented in the early stage of the diagnosis of rectal prolapse. The women who test positive for depressive symptoms need to be encouraged to obtain appropriate physical and psychological treatments.

This study had a few limitations. One is that the participants of this study were a convenience sample of women of 50 years of age or over diagnosed with rectal prolapse, recruited from a single colorectal surgery clinic. Therefore, the study findings cannot be generalized to all women diagnosed with rectal prolapse. Another is that cross-sectional nature does not allow causal inference. A longitudinal study design may be required to develop appropriate ways to address the physical symptoms, depressive symptoms, and QOL of women seeking non-surgical treatment for rectal prolapse, starting with diagnosis and during follow-up. Despite these limitations, however, this study had a strength as it examined the interaction effects of physical symptoms and depressive symptoms on the QOL of women seeking care for rectal prolapse. Further studies are needed to accumulate robust evidence supporting the interaction effects of physical and psychological symptoms on the QOL of women with rectal prolapse.

In conclusion, this study supports that physical symptoms related to rectal prolapse are closely correlated with depressive symptoms and their interaction has a significant influence on the QOL of women seeking care for rectal prolapse. Furthermore, depressive symptoms had a main effect on their QOL. Therefore, physical and depressive symptoms should be considered together to improve the QOL in women seeking care for rectal prolapse. Based on the findings, early identification of depressive symptoms and monitoring of physical symptoms are required, as are nursing interventions and medical treatments to decrease physical and depressive symptoms related to rectal prolapse.

\section{ORCID}

Hee Moon, https://orcid.org/0000-0001-7294-2038

Youngrye Park, https://orcid.org/0000-0002-1667-8129

Mili Kim, https://orcid.org/0000-0002-8555-2044

Seonah Lee, https://orcid.org/0000-0002-4669-4613

\section{Authors' contributions}

Conceptualization: Moon H, Park Y, Kim M, Lee S; Data collection: Moon H, Park Y, Kim M; Formal analysis: Moon H, Park Y, Kim M, Lee S; Writing-original draft: Moon H, Park Y, Lee S; Writing-review \& editing: Moon H, Park Y, Lee S.

\section{Conflict of interest}

The authors declared no conflict of interest.

\section{Funding}

None.

\section{Data availability}

The dataset file is availabale from Harvard Dataverse at https:// doi.org/10.7910/DVN/CJNPAB.

\section{Acknowledgments}

The authors sincerely thank the participants for taking part in the survey.

\section{References}

1. Neshatian L, Lee A, Trickey AW, Arnow KD, Gurland BH. Rectal prolapse: age-related differences in clinical presentation and what bothers women most. Dis Colon Rectum. 2021;64(5):609-616. https://doi.org/10.1097/DCR000000 0000001843

2. Healthcare Bigdata Hub. Disease subclassification statistics information [Internet]. Wonju: Health Insurance Review \& Assessment Service; 2020 Jan [cited 2020 Apr 18]. Available from: http://opendata.hira.or.kr/op/opc/olap4thDsInfo.do 
3. Kumar N, Kumar D. Fecal incontinence and rectal prolapse. Indian J Gastroenterol. 2020;38:465-469. https://doi. org/10.1007/s12664-020-01014-1

4. Tou S, Brown SR, Nelson RL. Surgery for complete (full-thickness) rectal prolapse in adults. Cochrane Database Syst Rev. 2015;2015(11):CD001758. https://doi.org/10.1002/ 14651858.CD001758.pub3

5. Giannini A, Russo E, Cano A, Chedraui P, Goulis DG, Lambrinoudaki I, et al. Current management of pelvic organ prolapse in aging women: EMAS clinical guide. Maturitas. 2018; 110:118-123. https://doi.org/10.1016/j.maturitas.2018.02.004

6. Mirskaya M, Lindgren EC, Carlsson IM. Online reported women's experiences of symptomatic pelvic organ prolapse after vaginal birth. BMC Womens Health. 2019;19(1):129. https://doi.org/10.1186/s12905-019-0830-2

7. Joodah S. Obsessive compulsive disorder and giant rectal prolapse. Psychiatry Ment Health Res. 2017;1(1):1-3.

8. Ai F, Deng M, Mao M, Xu T, Zhu L. Depressive symptoms screening in postmenopausal women with symptomatic pelvic organ prolapse. Menopause. 2018;25(3):314-319. https:// doi.org/10.1097/GME.0000000000001006

9. Toye F, Pearl J, Vincent K, Barker K. A qualitative evidence synthesis using meta-ethnography to understand the experience of living with pelvic organ prolapse. Int Urogynecol J. 2020;31(12):2631-2644. https://doi.org/10.1007/s00192-02004494-Z

10. Zeleke BM, Ayele TA, Woldetsadik MA, Bisetegn TA, Adane AA. Depression among women with obstetric fistula, and pelvic organ prolapse in northwest Ethiopia. BMC Psychiatry. 2013;13:236. https://doi.org/10.1186/1471-244X-13-236

11. Pizarro-Berdichevsky J, Hitschfeld MJ, Pattillo A, Blumel B, Gonzalez S, Arellano M, et al. Association between pelvic floor disorder symptoms and QoL scores with depressive symptoms among pelvic organ prolapse patients. Aust N Z J Obstet Gynaecol. 2016;56(4):391-397. https://doi.org/10. 1111/ajo.12467

12. Bradley CS, Brown HW, Shippey SS, Gutman RE, Andy UU, Yurteri-Kaplan LA, et al. Generic health-related quality of life in patients seeking care for pelvic organ prolapse. Female Pelvic Med Reconstr Surg. 2021;27(6):337-343. https://doi. org/10.1097/SPV.0000000000001069

13. Lavrakas PJ. Encyclopedia of survey research methods, Vols. 1-10. Thousand Oaks, CA: Sage Publications; 2008.

14. Kerlinger FN. Foundations of behavioral research. 3rd ed. New York, NY: Holt, Rinehart and Winston; 1986.

15. Mattsson NK, Karjalainen PK, Tolppanen AM, Heikkinen
AM, Sintonen H, Härkki P, et al. Pelvic organ prolapse surgery and quality of life-a nationwide cohort study. Am J Obstet Gynecol. 2020;222(6):588.e1-588.e10. https://doi.org/10. 1016/j.ajog.2019.11.1285

16. Ghetti C, Lowder JL, Ellison R, Krohn MA, Moalli P. Depressive symptoms in women seeking surgery for pelvic organ prolapse. Int Urogynecol J. 2010;21(7):855-860. https://doi. org/10.1007/s00192-010-1106-4

17. Kang H, Yeon K, Han ST. A review on the use of effect size in nursing research. J Korean Acad Nurs. 2015;45(5):641-649. https://doi.org/10.4040/jkan.2015.45.5.641

18. Barber MD, Kuchibhatla MN, Pieper CF, Bump RC. Psychometric evaluation of 2 comprehensive condition-specific quality of life instruments for women with pelvic floor disorders. Am J Obstet Gynecol. 2001;185(6):1388-1395. https:// doi.org/10.1067/mob.2001.118659

19. Yoo EH, Jeon MJ, Ahn KH, Bai SW. Translation and linguistic validation of Korean version of short form of pelvic floor distress inventory-20, pelvic floor impact questionnaire-7. Obstet Gynecol Sci. 2013;56(5):330-332. https://doi.org/10.5468/ ogs.2013.56.5.330

20. Oh SM, Min KJ, Park DB. A study on the standardization of the hospital anxiety and depression scale for Koreans: a comparison of normal, depressed and anxious groups. J Korean Neuropsychiatr Assoc. 1999;38(2):289-296.

21. Snaith RP. The hospital anxiety and depression scale. Health Qual Life Outcomes. 2003;1:29. https://doi.org/10.1186/ 1477-7525-1-29

22. Zigmond AS, Snaith RP. The hospital anxiety and depression scale. Acta Psychiatr Scand. 1983;67(6):361-370. https://doi. org/10.1111/j.1600-0447.1983.tb09716.x

23. Kim SH, Jo MW, Ahn J, Ock M, Shin S, Park J. Assessment of psychometric properties of the Korean SF-12 v2 in the general population. BMC Public Health. 2014;14:1086. https://doi. org/10.1186/1471-2458-14-1086

24. Ware J Jr, Kosinski M, Keller SD. A 12-Item Short-Form Health Survey: construction of scales and preliminary tests of reliability and validity. Med Care. 1996;34(3):220-233. https:// doi.org/10.1097/00005650-199603000-00003

25. Choi YS, Kim DJ, Lee KY, Park YS, Cho KJ, Lee JH, et al. How does chronic back pain influence quality of life in Koreans: a cross-sectional study. Asian Spine J. 2014;8(3):346-352. https://doi.org/10.4184/asj.2014.8.3.346

26. Andy UU, Harvie HS, Pahwa AP, Markland A, Arya LA. The relationship between fecal incontinence, constipation and defecatory symptoms in women with pelvic floor disorders. 
Neurourol Urodyn. 2017;36(2):495-498. https://doi.org/10.10 02/nau.22964

27. Vasconcelos Neto JA, Vasconcelos CTM, Regadas SMM, Bezerra LRPS, Lustosa KA, Karbage SAL. Clinical impact of bowel symptoms in women with pelvic floor disorders. Int Urogynecol J. 2017;28(9):1415-1420. https://doi.org/10.1007/ s00192-017-3288-5
28. Price PC, Jhangiani RS, Chiang ICA, Leighton DC, Cuttler C. Research methods in psychology. 3rd ed. Pullman, WA: Washington State University; 2017.

29. Mazi B, Kaddour O, Al-Badr A. Depression symptoms in women with pelvic floor dysfunction: a case-control study. Int J Womens Health. 2019;11:143-148. https://doi.org/10.21 47/IJWH.S187417 